\title{
Aging with HIV Infection and Locomotors Disorders: Experience of the Infectious and Tropical Diseases Unit, Abidjan, Côte d'Ivoire
}

AK Tanon ${ }^{1,2 *}$, Z Diallo1, S Lenaud ${ }^{3}$, S Niangoran ${ }^{3}$, K Peres $^{4}$, SP Eholié1,2 and AR Kakou ${ }^{1,2}$

1 Infectious and Tropicale Diseases Unit, Treichville teaching hospital, Abidjan, Côte d'Ivoire

${ }^{2}$ Training and Research Unit of Medical Sciences, University Félix Houphouët Boigny, Côte d'Ivoire

${ }^{3}$ Research Program on HIVIAIDS and Associated Diseases, Site ANRS of Côte d'Ivoire

${ }^{4}$ Institute of Public Health Epidemiology and Development from the University of Bordeaux, Bordeaux, France

\begin{abstract}
Objective: The aim of the study was to estimate the prevalence of locomotor disorders among people living with HIV in Abidjan.

Methods: A cross-sectional study was conducted in April-July 2014 at the Department of Infectious and Tropical Diseases in Abidjan. Data were collected with a questionnaire and four tests of locomotor function: 4-m walking speed, five timings from sit-to-stand, the timed "up and go" test and standing on one leg with the eyes closed. Logistic regression models were used to find factors associated with locomotors disorders.

Results: Of the 308 patients included in our study, $67.5 \%$ were women, and the median age was 45 years. The median duration of HIV infection was 91 months, and $97.4 \%$ were receiving antiretroviral therapy. The locomotor test that showed the most frequent alteration ( $87 \%$ of patients) was standing on one leg with the eyes closed. The prevalence of locomotors disorders was estimated to be $34 \%$ (95\% confidence interval $(\mathrm{Cl}), 28.8-39.4)$. In the multivariate analysis, age (odds ratio $(\mathrm{OR}), 1.9 ; 95 \% \mathrm{Cl}, 1.1-3.2 ; p=0.014)$ and body mass index $(\mathrm{OR}, 2.5 ; 95 \% \mathrm{Cl}$, 1.5-4.3; $p=0.001$ ) were significantly associated with the presence of locomotors disorders. No association was found with time since diagnosis of HIV infection or antiretroviral therapy.
\end{abstract}

Conclusion: The prevalence of locomotors disorders among people living with HIV is high. Strategies should be developed to screen and treat these disorders in order to limit functional impairment in this population.

Keywords: Locomotors disorder; HIV infection; Ageing

\section{Introduction}

HIV infection has become a chronic disease. Effective support through antiretroviral drugs to control viral replication, gives people living with HIV a life expectancy close to that of the general population. However, we currently observe in that population, a growing number of co-morbidities associated with ageing, but that occurs usually earlier than in the general population [1] Factors associated with the occurrence of these events are related to chronic inflammation due to HIV, the duration of infection, no control of viral replication, age, gender, geographical origin and ARV treatment. These findings have led some authors to refer to the concept of an "accelerated ageing" from multifactorial origin affecting that population including the locomotors functions $[1,2]$. In the general population, locomotors functions deteriorate with age and are associated with risk of falls and with limitations in daily activities. A decrease in skeletal muscle strength is considered as key element of frailty and loss of autonomy [2].

Data from a cross-sectional survey done in 2002 suggest that up to $30 \%$ of the patients infected with HIV have complaints about their locomotor function [3] comparatively to non-HIV persons estimated with the Dijon scale [4]. In sub-Saharan Africa, in our knowledge, there is no study done on the movement disorders in HIV-positive patients, because the assessment of these disorders does not yet part of the recommendations in care of people living with HIV. That's why we were motivated to do a cross-sectional survey in 2014 to estimate the prevalence of locomotors disorders in HIV-positive patients follow-up in the Infectious Diseases Unit, find the factors involved so and identify some risk groups who will benefit from strategies of prevention.

\section{Materials and Methods}

\section{Study population}

We conducted a cross-sectional study at Treichville teaching hospital among HIV-infected patient receiving ART during at least 6 and follow-up in the Infectious and Tropical Diseases Unit from 22 April and 31 July 2014. In this context, all people over 18 years with a diagnosis of HIV infection who gave their written consent for participation were included. Patients with opportunistic infections, cancer or respiratory or cardiovascular diseases and pregnant women, who might have limited performance in the tests, were not included.

\section{Study conduct}

A questionnaire and an assessment of locomotor function in four tests were used to collect data. The date of diagnosis and type of HIV infection, CDC stage, lowest CD4 count, latest CD4 count, latest viral load and current antiretroviral treatment were collected from the patient care records. The questionnaire was administered face to

*Corresponding author: Dr. Aristophane Tanon, Infectious and Tropical Diseases Unit. Treichville Teaching Hospital, 01, BP V3, Abidjan, Côte d'Ivoire; Tel: 22502001486; E-mail: aristotanon@yahoo.fr

Received March 07, 2017; Accepted March 18, 2017; Published March 25, 2017

Citation: Tanon AK, Diallo Z, Lenaud S, Niangoran S, Peres K, et al. (2017) Aging with HIV Infection and Locomotors Disorders: Experience of the Infectious and Tropical Diseases Unit, Abidjan, Côte d'Ivoire. J AIDS Clin Res 8: 680. doi: 10.4172/2155 6113.1000680

Copyright: ( 2017 Tanon AK, et al. This is an open-access article distributed unde the terms of the Creative Commons Attribution License, which permits unrestricted use, distribution, and reproduction in any medium, provided the original author and source are credited. 
face to elicit sociodemographic characteristics, the characteristics of HIV infection, antiretroviral treatment (initial and current regimen, compliance, reasons for changing treatment) and clinical data. Physical activity was scored on the Dijon scale [4]. Functional motor limitations were measured as the level of personal capacity to perform (alone, without technical help) basic actions such as walking, kneeling, using the hands, picking up an object and carrying $5 \mathrm{~kg}$ for $10 \mathrm{~m}$. The limitations were scored as performance "without difficulty" "with some difficulty", "with great difficulty" or "cannot do at all" [5]. Locomotor function was assessed in a battery of standardized, validated tests by trained personnel [5-8]:

"Five-times sit-to-stand" measures the strength of the lower limbs and the ability of the muscles to contract to produce movement. The participant sits in a standard wheelchair (height, $45 \mathrm{~cm}$ ) with the back against the chair and arms folded across the chest. After a practice test, the participant is asked to stand up and sit down fully five times as soon as possible thereafter, without using the arms to push against the chair $[9,10]$.

Speed of walking $4 \mathrm{~m}$ is a simple test in which the patient is asked to walk normally from the starting point to the arrival of the defined route. The speed of walking is measured in $\mathrm{m} / \mathrm{s}$.

Timed up-and-go is a clinical test of locomotion and balance, which involves measuring the mobility of a patient from seated to standing. The patient is asked to get up from a chair with a backrest, walk $3 \mathrm{~m}$ and then return to the chair. The score is given as the time in seconds.

In the "one-leg standing with eyes closed" test (Berg test), the subject is asked to remain as long as possible on the leg of his or her choice with the eyes closed, without moving and without support. An abnormal score is given if the participant fails to stand on one leg for at least $5 \mathrm{~s}$; a shorter time predicts a very high risk for falls. The sensitivity is $37 \%$ and the specificity $76 \%$. It provides an excellent index of postural ageing from as early as 45 years in the general population [10].

The presence of musculoskeletal disorder was defined by poor performance in more than one of these clinical tests, as defined in the literature [2,9].

\section{Statistical analyses}

A descriptive analysis was made for the entire study population. Missing data were recorded only for viral load and processed by the single imputation method based on the median. The results are expressed as median \pm interquartile range (IQR) for quantitative variables and frequency with $95 \%$ confidence intervals (CIs) for categorical variables. The prevalence of locomotor disorders is expressed as a percentage with its $95 \%$ CI. The Pearson chi-square test was used to compare variables between the groups with and without locomotor disorders. All tests used were two-sided with a significance level set at 0.05 .

Associated factors were analysed in a logistic regression model. The dependent variable was the presence of locomotor disorders. The association between a risk factor and the dependent variable was estimated by root cause analysis approval (Rca) in univariate analysis at the $25 \%$ significance level. Multivariate analysis was used to estimate the adjusted root cause analysis approval for each selected factor. At each step, the presence of confounding factors was monitored. The adequacy of the model was tested by the "goodness of fit" test. All statistical analyses were performed with STATA software version 11 .

\section{Results}

\section{Patients and characteristics}

Of the 6405 patients who presented to the Service for clinical or laboratory monitoring, consultation or for their monthly allocation of antiretroviral treatment, 226 were ineligible because they were hospitalized. Of the remaining 6179 patients, 308 were approached by the convenience method to participate in the study. None refused.

Our study sample comprised 208 women (67.5\%) and 100 men (32.5\%), giving a sex ratio of men to women of 0.48 . The sociodemographic characteristics are shown in Table 1 . The median age of the participants was 45.4 years (IQR=38-51); $44.2 \%$ lived with a partner and $37.7 \%$ had secondary-school education. Most of the participants $(84.1 \%)$ had a professional activity, $6.8 \%$ were pensioners and $9.1 \%$ were unemployed. The median weight was $65 \mathrm{~kg}(\mathrm{IQR}=58$ 74 ) and the median body mass index (BMI) was $23.1 \mathrm{~kg} / \mathrm{m}^{2}$ (IQR=21.226.9). Small proportions of participants used alcohol (13.6\%), tobacco (1.3\%) or drugs $(1.3 \%)$

\section{Physical activity and functional limitations}

All participants answered questions about functional limitations and physical activity; 199 were physically active (64.6\%). Motor limitations were identified in certain daily activities, including walking for $500 \mathrm{~m}$ on flat ground without assistance $(8.1 \%)$, walking up and down a flight of stairs without help (16.2\%), raising the arms (2.9\%) and carrying a $5 \mathrm{~kg}$ bag and walking $10 \mathrm{~m}(11.4 \%)$. Functional limitations were observed in the lower limbs in $35.7 \%$ of patients and in the upper limbs in $2.9 \%$.

\section{Locomotor tests}

The test that showed the greatest alteration was standing on one leg with the eyes closed, most patients (87.0\%) showing results considered to be pathological. Pathological results were obtained in $9.7 \%$ of patients for getting up and down from a chair five times and in $4.9 \%$ of patients for walking $4 \mathrm{~m}$. The median time for standing on one leg was $3.1 \mathrm{~s}$ (IQR=1.9-4.8) (Table 2), while $28.9 \%$ of patients had a poor score in the "timed up and go" test, with a median of $13.3 \mathrm{~s}(\mathrm{IQR}=11.9-15.4)$.

Pathological results in at least one test were found for 176 patients

\begin{tabular}{|c|c|c|c|}
\hline Parameters & & \\
\hline Age (years), median (IQR) & & 45.4 & $(38-51)$ \\
\hline Female gender, n (\%) & & 208 & $(67.5)$ \\
\hline Other nationality, n (\%) & & 34 & $(11.1)$ \\
\hline Marital status, n (\%) & Living couple & 136 & $(44.2)$ \\
\hline Level of education, n (\%) & None & 68 & $(22.1)$ \\
\hline & Primary & 86 & $(27.9)$ \\
\hline Professional activity, $\mathrm{n}(\%)$ & Secondary & 116 & $(37.7)$ \\
\hline & Higher & 38 & $(12.3)$ \\
\hline Weight (kg), median (IQR) & Active & 259 & $(84.1)$ \\
\hline BMI (kg/m $\left.{ }^{2}\right)$, median (IQR) & & 21 & $(6.8)$ \\
\hline Alcohol, $\mathrm{n}(\%)$ & & 65 & $(58-74)$ \\
\hline Smoking, $\mathrm{n}(\%)$ & Retired & 23.9 & $(21.2-26.9)$ \\
\hline & Former smoker & 33 & $(10.7)$ \\
\hline & Current smoker & 4 & $(1.3)$ \\
\hline Drug use, n (\%) & Nonsmoker & 271 & $(88.0)$ \\
\hline
\end{tabular}

Table 1: Social and demographic characteristics of patients. 
Citation: Tanon AK, Diallo Z, Lenaud S, Niangoran S, Peres K, et al. (2017) Aging with HIV Infection and Locomotors Disorders: Experience of the Infectious and Tropical Diseases Unit, Abidjan, Côte d'Ivoire. J AIDS Clin Res 8: 680. doi: 10.4172/2155-6113.1000680

Page 3 of 5

\begin{tabular}{|c|c|c|c|c|}
\hline Characteristics & $\begin{array}{l}\text { Total } \\
\text { N (\%) }\end{array}$ & $\begin{array}{c}\text { Without } \\
\text { disorders } \\
(n=203)(\%)\end{array}$ & $\begin{array}{c}\text { With } \\
\text { disorders } \\
(n=105)(\%)\end{array}$ & $P^{*}$ \\
\hline Age (years) & & & & 0.007 \\
\hline$\leq 45$ & $150(48.7)$ & $110(54.2)$ & $40(38.1)$ & \\
\hline$>45$ & $158(51.3)$ & $93(45.8)$ & $65(61.9)$ & \\
\hline Gender & & & & 0.427 \\
\hline Male & $100(32.5)$ & $69(34.0)$ & $31(29.5)$ & \\
\hline Female & $208(67.5)$ & $134(66.0)$ & $74(70.5)$ & \\
\hline BMI $\left(\mathrm{kg} / \mathrm{m}^{2}\right)$, median $(\mathrm{IQR})$ & $24(21-27)$ & $23(21-26)$ & $25(21-29)$ & 0.012 \\
\hline Level of education, $n(\%)$ & & & & 0.048 \\
\hline None & $68(22.1)$ & $36(17.7)$ & $32(30.5)$ & \\
\hline Primary & $86(27.9)$ & $61(30.1)$ & $25(23.8)$ & \\
\hline Secondary & $116(37.7)$ & 77 (37.9) & $39(37.1)$ & \\
\hline Higher & $38(12.3)$ & $29(14.3)$ & $9(8.6)$ & \\
\hline $\begin{array}{l}\text { Duration of HIV infection } \\
\text { (months), median (IQR) }\end{array}$ & $91(58-110)$ & $91(57-110)$ & $88(58-110)$ & 0.718 \\
\hline HIV type & & & & 0.986 \\
\hline HIV1 & $285(92.5)$ & $188(92.7)$ & $97(92.4)$ & \\
\hline HIV2 & $12(3.9)$ & $8(3.9)$ & $4(3.8)$ & \\
\hline HIV1+2 & $11(3.6)$ & $7(3.4)$ & $4(3.8)$ & \\
\hline CDC stage & & & & 0.34 \\
\hline A & $47(15.2)$ & $33(16.3)$ & $47(15.2)$ & \\
\hline B & $194(63.0)$ & $122(60.1)$ & $194(63.0)$ & \\
\hline $\mathrm{C}$ & $67(21.8)$ & $48(23.6)$ & $67(21.8)$ & \\
\hline $\begin{array}{l}\text { Lowest CD4 count (/ } \\
\left.\qquad \mathrm{mm}^{3}\right)\end{array}$ & & & & 0.026 \\
\hline$<200$ & $200(64.9)$ & $123(61.5)$ & $77(38.5)$ & \\
\hline$\geq 200$ & $108(35.1)$ & $80(74.1)$ & $28(25.9)$ & \\
\hline $\begin{array}{l}\text { Most recent CD4 count } \\
\qquad\left(/ \mathrm{mm}^{3}\right)\end{array}$ & & & & 0.121 \\
\hline$<200$ & $37(12)$ & $29(14.3)$ & $8(7.6)$ & \\
\hline 200-499 & $144(46.8)$ & $88(43.3)$ & $56(53.3)$ & \\
\hline$\geq 500$ & $127(41.2$ & $86(42.4)$ & $41(39)$ & \\
\hline $\begin{array}{l}\text { Most recent viral load } \\
\quad(\text { copies } / \mathrm{mL})\end{array}$ & & & & 0.48 \\
\hline$<200$ & $253(82.1)$ & $169(83.3)$ & $84(80.0)$ & \\
\hline$\geq 200$ & $55(17.9)$ & $34(16.7)$ & $21(20.0)$ & \\
\hline $\begin{array}{l}\text { Type of antiretroviral } \\
\text { treatment }\end{array}$ & & & & 0.24 \\
\hline Untreated & $7(2.3)$ & $6(3.0)$ & $1(1.0)$ & \\
\hline $2 \mathrm{NI}+\mathrm{NNI}$ & $188(61.0)$ & $118(58.1)$ & $70(66.7)$ & \\
\hline $2 \mathrm{NI}+\mathrm{PI}$ & $113(36.7)$ & 79 (38.9) & $34(32.3)$ & \\
\hline Use of alcohol & & & & 0.417 \\
\hline Yes & $42(13.6)$ & $30(14.8)$ & $12(11.4)$ & \\
\hline No & $266(86.4)$ & $173(85.2)$ & $93(88.6)$ & \\
\hline Use of tobacco & & & & 0.334 \\
\hline Smoker & $37(12.0)$ & $27(13.3)$ & $10(9.5)$ & \\
\hline Nonsmoker & $271(88.0)$ & $176(86.7)$ & $95(90.5)$ & \\
\hline $\begin{array}{l}\text { Duration of exposure to } \\
\text { antiretroviral treatment } \\
\text { (months), median }\end{array}$ & $88(49-105)$ & $75(38-103)$ & $83(48-104)$ & 0.354 \\
\hline
\end{tabular}

* Pearson chi-2 test

NI: Nucleosidic Inhibitor; NNI: Non Nucleosidic Inhibitor; PI: Protease Inhibitor

Table 2: Characteristics of patients with and without locomotor disorders.

(56.2\%); only 30 patients $(9.7 \%)$ performed well in all tests. None of the patients had four abnormal tests. Thus, the prevalence of locomotor disorders was estimated to be $34.1 \%$ (95\% CI, 28.8-39.4).

Patients who had locomotor disorders $(n=105)$ were significantly

\begin{tabular}{|c|c|c|}
\hline Factors & $\begin{array}{c}\text { Adjusted OR and } \\
95 \% \mathrm{Cl}\end{array}$ & $p$-value \\
\hline Age (years) & & 0.014 \\
\hline$\leq 45$ & 1.0 & \\
\hline$>45$ & $1.9(1.1-3.1)$ & \\
\hline \multicolumn{2}{|c|}{ BMI $\left(\mathrm{kg} / \mathrm{m}^{2}\right)$} & 0.001 \\
\hline$<25$ & 1.0 & \\
\hline$\geq 25$ & $2.5(0.9-3.5)$ & \\
\hline \multicolumn{2}{|c|}{ Level of education } & 0.136 \\
\hline None & 1.0 & \\
\hline Primary & $0.5(0.2-0.9)$ & 0.037 \\
\hline Secondary & $0.7(0.3-1.3)$ & 0.233 \\
\hline Higher & $0.4(0.1-0.9)$ & 0.073 \\
\hline Dijon physical activity score & & 0.003 \\
\hline Sedentary & 1.0 & \\
\hline Active & $0.4(0.3-0.8)$ & \\
\hline Lowest $\mathrm{CD} 4$ count $\left(/ \mathrm{mm}^{3}\right)$ & & 0.058 \\
\hline$<200$ & 1.0 & \\
\hline$\geq 200$ & $0.6(0.3-1.1)$ & \\
\hline Most recent CD4 count $\left(/ \mathrm{mm}^{3}\right)$ & & 0.948 \\
\hline$\geq 500$ & 1.0 & \\
\hline $200-499$ & $1.9(0.8-4.9)$ & 0.154 \\
\hline$<200$ & $1.3(0.5-3.4)$ & 0.559 \\
\hline \multicolumn{2}{|c|}{ Antiretroviral treatment } & 0.573 \\
\hline Untreated & 1.0 & \\
\hline $2 \mathrm{NI}+\mathrm{NNI}$ & $3.0(0.3-27.7)$ & 0.332 \\
\hline $2 \mathrm{NI}+\mathrm{PI}$ & $2.4(0.3-22.3)$ & 0.453 \\
\hline
\end{tabular}

NI: Nucleosidic Inhibitor; NNI: Non Nucleosidic Inhibitor; PI: Protease Inhibitor

Table 3: Factors associated with locomotors disorders in the logistic regression model, multivariate analysis.

older $(P<0.007)$, had secondary education $(P<0.048)$, were overweight $\left(\mathrm{BMC} \geq 25 \mathrm{~kg} / \mathrm{m}^{2} ; P<0.012\right)$ and had a lower $\mathrm{CD} 4$ lymphocyte count $\left(<200 / \mathrm{mm}^{3}\right)$ than patients who did not have a locomotor disorder $(n=203)$. No significant difference in the presence of locomotor disorders was found by sex $(P=0.427)$, smoking $(P=0.334)$, alcohol use $(P=0.417)$, duration of HIV infection $(P=0.718)$, antiretroviral therapy $(P=0.24)$, length of exposure to antiretrovirals $(P=0.354)$ or viral load $(P=0.48)$ (Table 2).

Table 3 shows the factors associated with the presence of locomotor disorders in the final multivariate analysis. Locomotor disorders among people living with HIV were significantly associated with age $(P=0.014$, adjusted root cause analysis approval $=1.9 ; 95 \% \mathrm{CI}, 1.1-3.1)$ and BMI ( $P=0.001$, adjusted root cause analysis approval, $2.5 ; 95 \% \mathrm{CI}$, 0.9-3.5). Patients aged $>45$ years were 1.9 times more likely to have a locomotor disorder than those aged $<45$ years. Patients with a BMI $>25$ $\mathrm{kg} / \mathrm{m}^{2}$ were at a 2.5 times greater risk for locomotor disorders (OR, 2.5; 95\% CI, 0.9-3.5). The probability of locomotor disorders was reduced with physical activity $(\mathrm{OR}=0.4 ; 95 \% \mathrm{CI}, 0.3-0.8 ; P=0.003)$ and with a lowest $\mathrm{CD} 4$ count $>200 / \mathrm{mm}^{3}$ (OR=0.6; 95\% CI, 0.3-1.1; $\left.P=0.058\right)$. No association was found with the most recent CD4 count $(P<0.948)$ or type of antiretroviral treatment $(P<0.573)$.

\section{Discussion}

The prevalence of locomotors disorders among people living with HIV infection was estimated to be $34.1 \%$ in this sample, similar to the findings in Columbia [3]. About one third of patients had pathological results in at least two tests. This finding is higher than that found by Nozères et al. of 29\% (95\% CI, 24-34), probably due to differences in 
Citation: Tanon AK, Diallo Z, Lenaud S, Niangoran S, Peres K, et al. (2017) Aging with HIV Infection and Locomotors Disorders: Experience of the Infectious and Tropical Diseases Unit, Abidjan, Côte d'Ivoire. J AIDS Clin Res 8: 680. doi: 10.4172/2155-6113.1000680

Page 4 of 5

the tests used and in sampling [11]. The descriptive analysis showed that all patients do not have the same problems. The test in which $87 \%$ of patients had a pathological result was standing on one foot with the eyes closed, which tests patients' balance. Pathological results were found for $28.9 \%$ of patients in the "timed up and go" test, $9.7 \%$ in the "fivetime sit-to-stand" test and $4.9 \%$ in the speed of walking $4 \mathrm{~m}$ test. In the study made by Richert et al. [5], the test with most frequent alterations was the "five-time sit-to-stand" (53.3\%), followed by the "timed up and go" test (10.5\%) and standing on one leg with the eyes closed $(9.9 \%)$. The "five-times sit-to-stand" test measures lower limb muscle strength and balance $[9,12]$. The characteristics of our population differed from those of Richert et al. [5]. Our sample was predominantly female $(67.53 \%)$ and the median age was 45.4 years, whereas the Bordeaux team studied a group consisting of $80 \%$ men with a median age of 47.6 years (IQR $=41.8-53.9)[5,13,14]$. Most studies show that the prevalence of these disorders is directly related to age $[2,9,10]$. Thus, $25 \%$ of people living with HIV infection who are $>45$ years and only $3-5 \%$ of people $>65$ years in the general population suffer from these disorders [2,5-7].

Deterioration of the balance function appeared to be the central element of the locomotors disorders in our patients. Conversely, Richert et al. [5] found that the only tests that showed significantly deteriorating function after a follow-up of two years were five times sitting and rising from a chair and a 6 min walk. The results of tests that more specifically assess balance, such as the "timed up and go", the Berg test or unipodal support with the eyes closed did not show deterioration [14]. The difference in results suggests strong involvement of reduced muscle function in our patients.

In our final multivariate analysis, age $>45$ years and having a BMI $>25 \mathrm{~kg} / \mathrm{m}^{2}$ were associated with the presence of locomotors disorders. Nutrition may affect locomotors disorders in people with HIV infection and Richert et al. also noted an effect of nutrition on physical performance [5]. They also highlighted a relation between BMI, physical performance in the "five-times sit-to-stand" and age. The interaction of BMI with locomotive disorders might be due to replacement of muscle mass with fat and the resulting decrease in physical performance [15].

We found no significant association with time since diagnosis of HIV infection, CD4 cell count, viral load or type or duration of antiretroviral treatment. We therefore found a significant association between performance in the "five-times sit-to-stand" test and duration of HIV infection, but no relation with either immuno-virological characteristics nor duration of exposure to antiretrovirals $[12,14]$. Richert et al. found that age, the presence of diabetes, cerebral complications related to AIDS and drug use were risk factors for the development of locomotors disorders [13].

Our findings indicate that, over time, the decline of locomotors functions in people with HIV infection is no longer determined by HIV infection but is due to external factors, even though the patients still carry an undetectable viral load. Physical activity appears to be a protective factor against the occurrence of locomotors disorders due to its therapeutic properties and its beneficial impact on primary prevention of cardiovascular disease [4].

\section{Conclusion}

Our work highlights a link between age, nutrition and the presence of locomotors disorders in people living with HIV infection. These disorders occurred mainly in people aged $>45$ years and with a BMI $\geq 25 \mathrm{~kg} / \mathrm{m}^{2}$, suggesting limitations in activities and important risk of falls. People who have physical activity are less likely to have a functional locomotors disorders, regardless the duration of exposure to antiretroviral treatment or length of HIV infection.

The ageing of people living with HIV infection is a major challenge for African societies, both socially and medically. A decrease in locomotor function is also problematic, as it has a significant impact on autonomy and entails a significant risk for falls. Practitioners should anticipate early, systematic, routine screening.

\section{Acknowledgement}

Aristophane Koffi Tanon: Lead author, wrote the article, Zélica Diallo: conducted the study for her thesis of Master 2, Public Health, Sévérin Lenaud Assisted in the design of the database, Serge Niangoran: Assisted in statistical analysis, Karine Pérès: Assisted in drafting the methodology of the study, Serge Eholié: Inspired the choice of the topic and led the drafting of the paper. Rigobert Kakou: Head of the infectious diseases Unit, authorized the study

Work carried out in the framework of a Françoise Barré-Sinoussi scholarship for excellence for a Master 2 in international public health at the University of Bordeaux, with the leadership team of the Bordeaux ISPED (Institute of Public Health and Development). Acknowledgement to Elisabeth Heseltine who has revised the article in English.

\section{Ethics' Aspects}

Our work has been done in context of thesis in Infectiology field. It has been approved by the department's head that is listed as the latest author. No invasive procedure has been done on patients outside the locomotor tests. We had the signed written consent of patients. So that, no submission was made to the country ethics committee. Patients' privacy was respected and their safety has been preserved. We noted no incidents throughout the study.

\section{References}

1. Effros RB, Fletcher CV, Gebo K, Halter JB, Hazzard WR, et al. (2008) Workshop on HIV infection and aging: What is known and future research directions. Clin Infect Dis 47: 542-553.

2. Balogun JA, Akindele KA, Nihinlola JO, Marzouk DK (1994) Age-related changes in balance performance. Disabil Rehabil 16: 58-62.

3. Rusch M, Nixon S, Schilder A, Braitstein P, Chan K, Hogg RS (2004) Impairments, activity limitations and participation restrictions: Prevalence and associations among persons living with HIVIAIDS in British Columbia. Health Qual Life Outcomes 2: 46.

4. Robert H, Casillas JM, Iskandar M, D'Athis P, Antoine D, et al. (2004) Le score d'activité physique de Dijon: Reproductibilité et corrélations avec l'aptitude physique de sujets sains âgés. Ann Réadapt Médecine Phys 47: 546-554.

5. Richert L, Dehail P, Mercié P, Dauchy F-A, Bruyand M, et al. (2011) High frequency of poor locomotor performance in HIV-infected patients. AIDS 25 797-805.

6. Podsiadlo D, Richardson S (1991) The timed "Up \& Go": A test of basic functional mobility for frail elderly persons. J Am Geriatr Soc 39: 142-148.

7. Beauchet O, Fantino B, Allali G, Muir SW, Montero-Odasso M, et al. (2011) Timed up and go test and risk of falls in older adults: A systematic review. J Nutr Health Aging 15: 933-938.

8. https://www.rheumatology.org/Practice/Clinical/Clinicianresearchers/ Outcomes_Instrumentation/Timed_Up_and_Go_(TUG)

9. Lord SR, Murray SM, Chapman K, Munro B, Tiedemann A (2002) Sit-tostand performance depends on sensation, speed, balance and psychological status in addition to strength in older people. J Gerontol A Biol Sci Med Sci 57: M539-M543.

10. Zhang F, Fernucci L, Culham E, Metter EJ, Guralnik J, et al. (2013) Performance on five times sit-to-stand task as a predictor of subsequent falls and disability in older persons. J Aging Health 25: 478-492.

11. Nozères A, Richert L, Delleci $C$, Mercié $P$, Bruyand $M$, et al. (2011) Evolution des troubles locomoteurs et posturaux chez les patients infectés par le $\mathrm{VIH}-1$ au sein de la cohorte ANRS CO3 Aquitaine. Ann Phys Rehabil Med 54: e135.

12. Dorfman D, Saag MS (2014) Decline in locomotor functions over time in HIVinfected patients. AIDS 28: 1531-1532. 
Citation: Tanon AK, Diallo Z, Lenaud S, Niangoran S, Peres K, et al. (2017) Aging with HIV Infection and Locomotors Disorders: Experience of the Infectious and Tropical Diseases Unit, Abidjan, Côte d'Ivoire. J AIDS Clin Res 8: 680. doi: 10.4172/2155-6113.1000680

Page 5 of 5

13. Richert L, Brault M, Mercié P, Dauchy FA, Bruyand M, et al. (2014) Groupe d'Epidémiologie Clinique du SIDA en Aquitaine (GECSA). Decline in locomotor functions over time in HIV-infected patients. AIDS 28: 14411449.

14. Richert L, Brault M, Mercié P, Dauchy F-A, Bruyand M, et al. (2014) Handgrip strength is only weakly correlated with physical function in well-controlled
HIV infection: ANRS CO3 aquitaine cohort. J Acquir Immune Defic Syndr 65: 25-27.

15. Buerinhg B, Kirshner F, Sun Z, Calabrese L (2012) The frequency of low muscular mass and its overlap of low bone mineral density and lipodystrophy in individuals with HIV - A pilot study using DXA total body composition analysis. J Clin Densitom 15: 224-232. 